DOI: $10.1002 / c s s c .201(($ will be completed by the editorial staff))

\title{
Influence of synthesis pH and oxidative strength of catalyzing acid on morphology and chemical structure of hydrothermal
}

\section{carbon}

\author{
Sylvia Reiche ${ }^{\star[a]}$, Natalia Kowalew ${ }^{[a]}$, Robert Schlögl ${ }^{[a, b]}$ \\ Dedication ((optional))
}

Specific control of morphology and chemical structure of hydrothermal carbon (HTC) is of crucial importance for its application, both in catalyst supports or electrochemical devices. Within the present study we show how the morphology, i.e. particles size and homogeneity, and the distribution of functional groups can be controlled by the control of the synthesis $\mathrm{pH}$ of the hydrothermal carbonization. The complementary analysis of liquid byproducts by HPLC provides useful information on the nature of the polymeric species produced during the poly-condensation in the hydrothermal process and reveals the potential implementation of the process into the biorefinery concept. The acidic byproduct levulinic acid and

\section{Introduction}

The synthesis of materials based on hydrothermal carbonization has been studied extensively during the last decade, due to its use of environmental friendly synthesis conditions and precursors, and the versatility of applications for the final product ${ }^{[1]}$. Another driving force of studying hydrothermal carbon synthesis is to gain mechanistic understanding of chemical production from biomass precursors. One of the central reactions in this field is the acid catalyzed dehydration of carbohydrates to form 5-hydroxymethyl furfural $(\mathrm{HMF})^{[2]}$. Often seen as unfortunate for the industrial synthesis of HMF based on renewable feedstocks, the reaction is accompanied by the formation of several site products. The major byproducts, which form solid deposits, are the so-called "humins"[3]. Humins and hydrothermal carbons are two terms for the same material, depending on whether the production of the carbon is intended or not. We show that by controlled synthesis specific functional materials can be produced from the condensation of glucose precursors. The systematic study of synthesis conditions, formation mechanism and final chemical structure of the HTC material is of crucial importance

[a] S. Reiche, N. Kowalew, Prof.R.Schlögl

Max Planck Institute for Chemical Energy Conversion (MPI CEC) Department Heterogeneous Reactions

Stiftstraße 34-36

45470 Mülheim an der Ruhr (Germany)

sylvia.reiche@cec.mpg.de

[b] Prof. R. Schlögl

Fritz Haber Institute of the Max Planck Society (FHI)

Department Inorganic Chemistry

Faradayweg 4-6

14195 Berlin (Germany)

Supporting information for this article is available on the WWW under $h$ ttp://dx.doi.org/10.1002/cssc.20xxxxxxx.((Please delete if not appropriate)) formic acid determine the hydrothermal carbonization autocatalytically by additional supply of protons to the reaction medium. Thus, for starting $\mathrm{pHs}>3$ only minor structural differences can be detected for the HTC. The use of oxidizing acids favors higher yields of HTC and improves the carbonization towards higher condensed carbon domains. Scale-up of the process in a stirred 2 I batch reactor favours carbonization leading to higher condensed carbonaceous products. The relative trends of $\mathrm{pH}$ variation are maintained.

for its intended application and will contribute to the successful implementation of HTC synthesis into biorefinery concepts as drafted in Scheme 1.

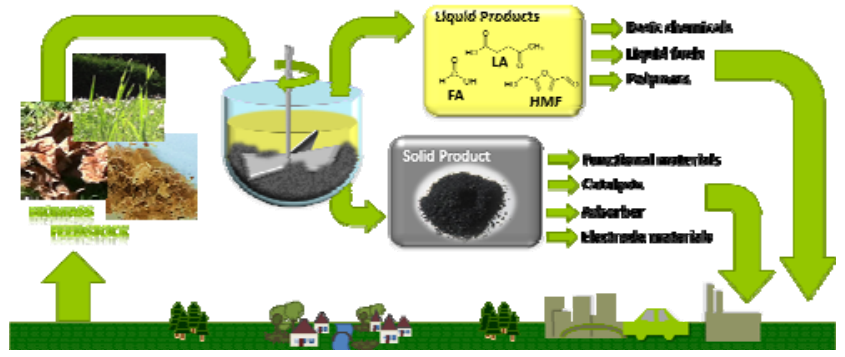

Scheme 1. Biorefinery concept including valuable products from hydrothermal carbon

Compositional variations of HTC were studied intensively by addition of different precursors ${ }^{[4,5]}$ for adopting chemical properties to the variety of potential applications such as adsorbents, catalysts or electrode materials. Although the successful reproduction of the synthesis procedure is challenging, due to the variety of synthesis parameter that crucially influence the final product, systematic studies on the influence of synthesis conditions are still rare ${ }^{[4,6]}$. In particular the synthesis $\mathrm{pH}$ controlling the acid catalyzed dehydration mechanism of the hydrothermal carbonization ${ }^{[3]}$, has not been studied systematically before. For this reason, we focused on the variation of synthesis $\mathrm{pH}$ in the present study. Another aspect of our investigations is the influence of the oxidizing strength of applied acid on both, the yield of the HTC as well as its chemical structure. 


\section{ChemSusChem}

\section{Full Papers \\ www.chemsuschem.org}

\section{Results and Discussion}

Influence of initial synthesis $\mathrm{pH}$ on $\mathrm{HTC}_{\mathrm{HNO}_{3}}$ morphology

For the $\mathrm{HTC}_{\mathrm{HNO}_{3}}$-materials, obtained by hydrothermal synthesis in nitric acid ( $\mathrm{pH} \mathrm{0-6),} \mathrm{first} \mathrm{differences} \mathrm{between} \mathrm{the} \mathrm{samples}$ were observed macroscopically. The materials synthesized at lower $\mathrm{pH}$ showed a linear decrease of powder density up to $\mathrm{pH} 3$ (Figure 1). For samples synthesized at $\mathrm{pH}>3$ similar powder densities of $0.06-0.07 \mathrm{~g} / \mathrm{ml}$ were determined. Together with the decrease in powder density, the color of the solid material changes from black to brown. Also here, the major transition can be observed at $\mathrm{pH} 3$.

The reasons for the macroscopic differences were found in the microscopic structure of the materials as analyzed by SEM (Figure 2). The particle size of the carbon shrinks gradually with increasing initial synthesis $\mathrm{pH}$. Furthermore, regions of fused particles were found for materials synthesized at $\mathrm{pH} 0$ and $\mathrm{pH} \mathrm{1}$, whereas the homogeneity in morphology of the samples improves with synthesis $\mathrm{pH}$. Typical particle sizes for the samples synthesized at $\mathrm{pH} 6$ and $\mathrm{pH} 3$ are $500 \mathrm{~nm}$ and 1 $\mu \mathrm{m}$, respectively. In both cases the spherical particles form loosely packed agglomerates which correspond to the fluffy macroscopic appearance of the low density materials. The particles in the hydrothermal carbon synthesized at $\mathrm{pH} 1$ are of broader size distribution of 4-15 $\mu \mathrm{m}$. Regions of particle aggregates can be found as well as films without defined structural features. The latter represent the main structural morphology of the sample synthesized at $\mathrm{pH} 0$.

The observations clearly show differences in the kinetics of nucleation and growth in the particle formation process for different synthesis $\mathrm{pH}$. Since the dehydration of glucose is acid catalyzed, acceleration of the formation of the hydroxymethyl furfural intermediate and its subsequent polymer is expected when lowering the $\mathrm{pH}$. The resulting phase separation of the increasingly hydrophobic products ideally forms spheres to minimize the surface tension. Such emulsion formation has been discussed before as possible explanation of the spherical character of the final particles ${ }^{[1,4]}$. Within the confined environment of the spherical polymer phase further internal condensation reactions occur leading to the actual carbonization and the evolution of conjugated structures. As a consequence, the product will contain higher amounts of cross connecting bonds, lose flexibility and coagulate in the shape determined by the initial polymer phase. Based on the observations from the scanning micrographs, we conclude that in the case of fast polymer formation at high proton concentration the extension of the polymeric phase and the progress of internal condensation is faster than the formation of spherical particles resulting in a distribution of shapes. In case of the synthesis at intermediate proton concentration between $\mathrm{pH} 3$ and 6 , the polymerization occurs slow enough to allow the diffusion controlled formation of a homogeneous emulsion of spherical shaped polymer phases. The color of the final material and the higher tendency of charging observed in the SEM for the material synthesized at $\mathrm{pH} 3$ or higher, point to a lower degree of internal condensation and less extended conjugated networks.

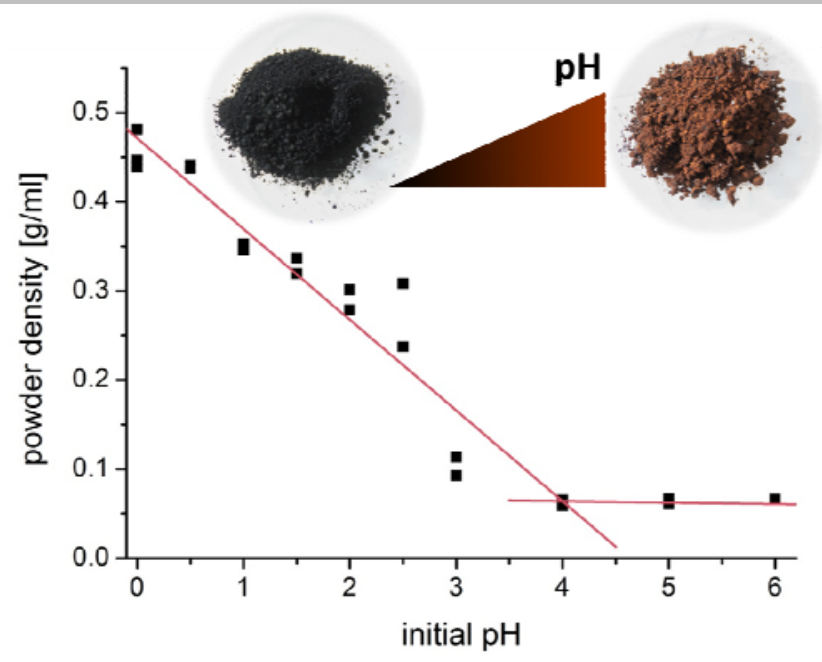

Figure 1. Decrease of powder density over $\mathrm{pH}$ accompanied by change in color from black to brown. For both properties the most pronounced transition occurred at $\mathrm{pH} 3$.
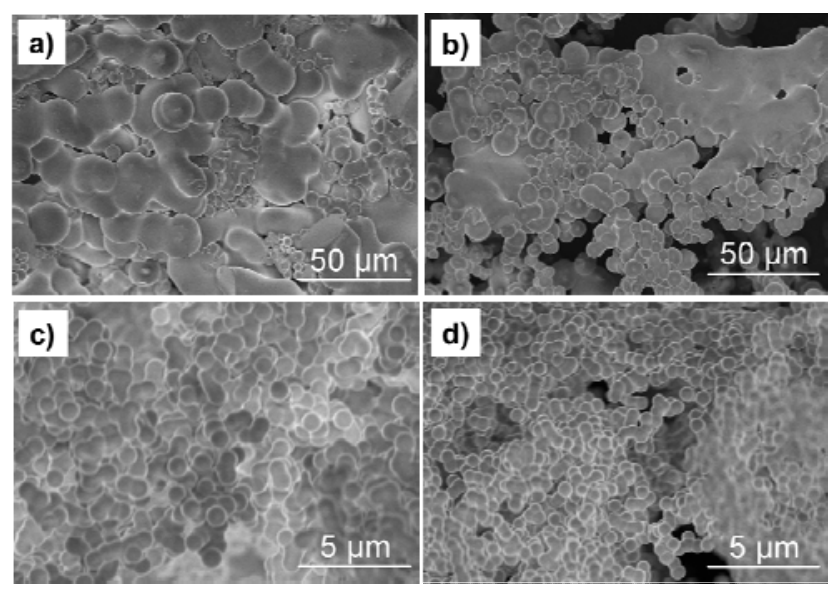

Figure 2. Scanning electron micrographs of hydrothermally synthesized carbon from glucose at a) $\mathrm{pH} 0, \mathrm{~b}) \mathrm{pH} 1, \mathrm{c}) \mathrm{pH} 3$ and d) $\mathrm{pH} 6$.

\section{Characterization of chemical structure of $\mathrm{HTC}_{\mathrm{HNO}}$ product}

The chemical structure of the HTC product was investigated by Raman spectroscopy, FT-IR (ATR) and TG-MS. By Raman spectroscopy (Figure 3 ), the intensity of the characteristic Dand G-bands at around 1360 and $1580 \mathrm{~cm}^{-1}$ significantly decrease with increasing synthesis $\mathrm{pH}$. In addition, significant beam damage was observed for the materials synthesized above $\mathrm{pH}$ 2. This and the fluorescence precluded identification of useful band structures but can be taken as indication for polycyclic molecular structure with few intermolecular covalent bonds. However, for materials synthesized at $\mathrm{pH} 0$ and 1 the existence of an extended carbonaceous structure was confirmed. The broad signals indicate that rather amorphous structures resulted from the hydrothermal synthesis ${ }^{[7]}$. 


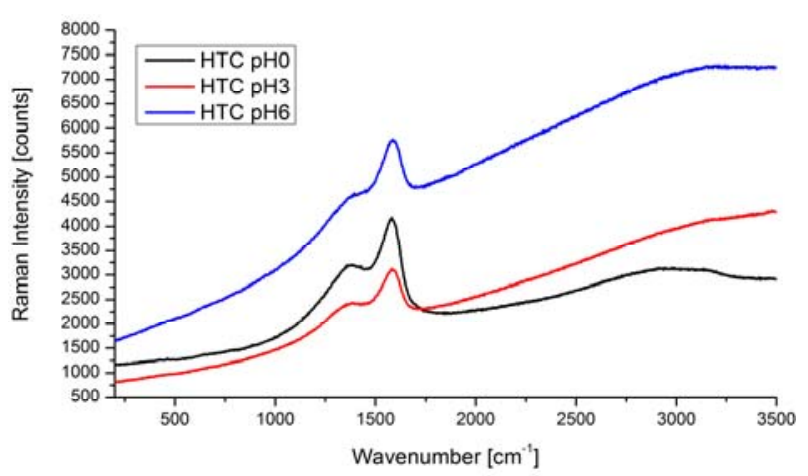

Figure 3. Comparison of Raman spectra for different initial synthesis $\mathrm{pH}$ $\left(\mathrm{HNO}_{3}\right)$ of hydrothermal carbon from glucose. The broad fluorescence background was not removed to illustrate the largely molecular nature of the "carbon" material.

In expected contrast to the Raman data, the IR spectra provide better signal to noise ratios with increasing synthesis $\mathrm{pH}$ of the hydrothermal carbonization (Figure 4). Although the assignment of the different bands varies throughout the literature, most authors report similar spectra ${ }^{[9]}$. Generally agreed is the assignment of the $(\mathrm{v}(\mathrm{O}-\mathrm{H})$ vibration at around $3400 \mathrm{~cm}^{-1}$, the $\mathrm{v}(\mathrm{C}-\mathrm{H})$ vibrations between $2960-2860 \mathrm{~cm}^{-1}$, the $\mathrm{v}(\mathrm{C}=\mathrm{O})$ band at around $1700 \mathrm{~cm}^{-1}$ and the $\mathrm{v}(\mathrm{C}=\mathrm{C})$ at 1610 $1630 \mathrm{~cm}^{-1}$. The interpretation of the vibrational modes at lower wavenumbers differs between phenolic structures or substituted aromatics, and furanic structural motives. Since the decision for either one of the models is rather difficult based on only IR spectra, we would like to focus on the clear intensity variation of the carbonyl-vibration versus the $\mathrm{C}=\mathrm{C}$ vibration observed for our materials prepared at various $\mathrm{pH}$ values. A clear decrease of the $\mathrm{C}=\mathrm{C}$ to $\mathrm{C}=\mathrm{O}$ band intensity ratio was observed with increasing synthesis $\mathrm{pH}$ pointing to higher abundance of carbonyl structural motives in the material synthesized at higher $\mathrm{pH}$. This is consistent with a lower extent of condensation reactions for lower concentrations of acid. In agreement with prior observations only minor structural changes were observed between the $\mathrm{pH}$ 4- and the $\mathrm{pH} 6$ samples.

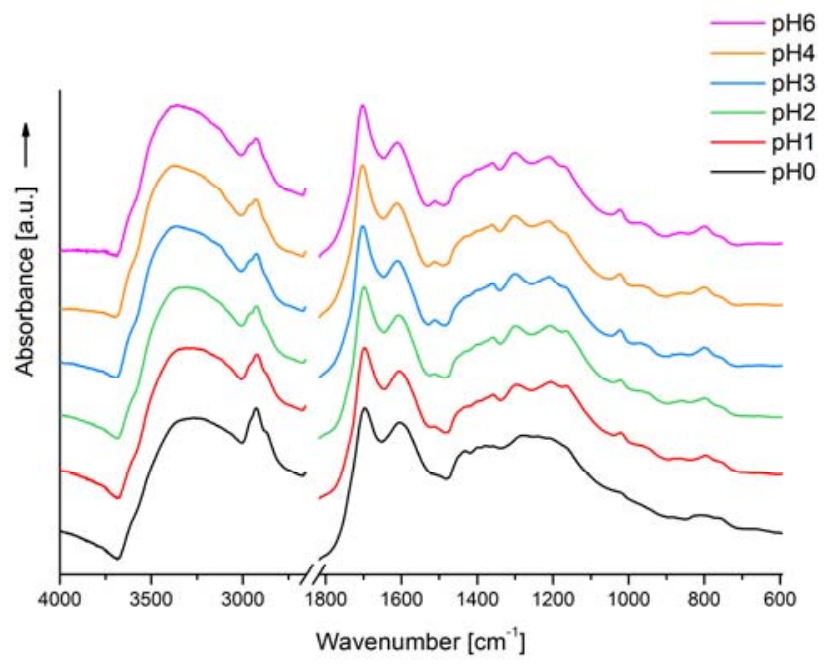

Figure 4. $\mathrm{FT}-\mathrm{IR}$ (ATR) spectra of $\mathrm{HTC}_{\mathrm{HNO}}$ synthesized at different initial synthesis $\mathrm{pH}$.

\begin{tabular}{|c|c|c|c|c|c|}
\hline $\mathrm{pH}^{[\mathrm{b}]}$ & C [wt\%] & $\mathrm{H}$ [wt\%] & $\mathrm{N}$ [wt\%] & $\mathrm{O}[\mathrm{wt} \%]^{[\mathrm{b}]}$ & $\begin{array}{c}\text { Residual } \\
\text { mass after } \\
\text { TG [m\%] }\end{array}$ \\
\hline 0 & $70.2 \pm 1.2$ & $5.6 \pm 0.6$ & $1.5 \pm 0.2$ & $23.2 \pm 0.4$ & 58.5 \\
\hline 1 & $69.6 \pm 1.3$ & $5.4 \pm 0.8$ & $0.38 \pm 0.01$ & $24.8 \pm 0.3$ & 55.7 \\
\hline 2 & $68.9 \pm 0.9$ & $5.9 \pm 1.8$ & $0.19 \pm 0.21$ & $25.2 \pm 1.0$ & 54.9 \\
\hline 3 & $68.6 \pm 0.9$ & $5.8 \pm 1.8$ & $<0.1$ & $25.6 \pm 0.8$ & 54.3 \\
\hline 4 & $67.7 \pm 0.7$ & $6.3 \pm 1.5$ & $<0.1$ & $25.7 \pm 1.7$ & 53.6 \\
\hline 5 & $68.1 \pm 0.5$ & $5.5 \pm 0.1$ & $<0.1$ & $26.5 \pm 0.4$ & 53.6 \\
\hline 6 & $67.7 \pm 0.0$ & $6.4 \pm 0.1$ & $<0.1$ & $25.9 \pm 0.1$ & 53.6 \\
\hline
\end{tabular}

[a] Standard deviations were determined by minimum two separate experiments at the same initial synthesis $\mathrm{pH}$. [b] Initial synthesis $\mathrm{pH}$. [c] The oxygen is determined indirectly by subtraction of the $\mathrm{C}-, \mathrm{H}$ - and $\mathrm{N}$-content from $100 \%$, since other elements can be excluded.

The solid products were investigated by TG-MS. The decrease of the residual mass over increasing synthesis $\mathrm{pH}$ is in agreement with the trend of decreasing carbon content (Table 1) found by chemical anaylsis. It supports the findings of the IR spectra, pointing to higher abundance of oxygen functional groups in the case of higher synthesis $\mathrm{pH}$. Based on the MS signals of the experiment (Figure 5) different types of oxygen functional groups can be distinguished. In case of the sample synthesized at $\mathrm{pH} 0$ a higher fraction of carboxylic acid functional groups was detected. Carboxylic acid functional groups decompose in $\mathrm{CO}_{2}$ (mass number 44$)^{[10]}$ and bind water (mass number 18). Neighboring carboxylic acid functional groups can form anhydrides under the evolution of water which is one reason for the detection of intense water signals also at higher temperatures. In addition, the desorption of surface water is more pronounced and slightly shifted to higher temperature for the material synthesized at $\mathrm{pH} 0$. This finding points to the higher abundance of hydrophilic functional groups that can undergo hydrogen bonding with the adsorbed water molecules.

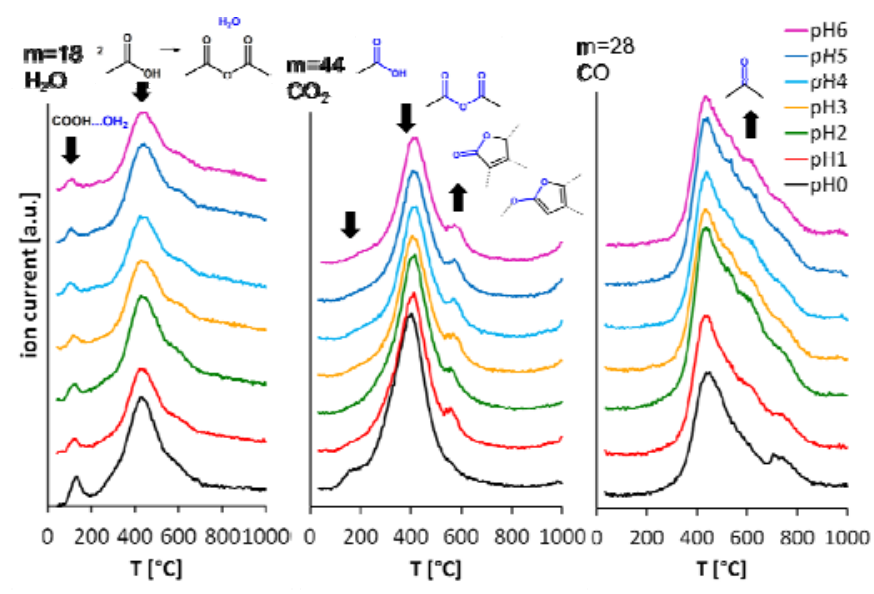

Figure 5. MS signals of TG-MS experiments on the samples prepared at various $\mathrm{pH}$ values. The arrows and structural formulae indicate likely assignments of the peak structures to typical functional groups.

The samples synthesized at higher $\mathrm{pH}$ exhibit a higher fraction of CO-evolving functional groups, such as carbonyl groups and in particular groups of thermostability between 500$700^{\circ} \mathrm{C}$. The higher abundance of carbonyl functional groups is in agreement with the IR data. In general it can be concluded 


\section{ChemSusChem}

\section{Full papers

that in the $\mathrm{pH}$ 0-sample most groups decompose at temperatures below $600^{\circ} \mathrm{C}$, whereas the samples synthesized at higher $\mathrm{pH}$ contain a higher fraction of groups that decompose at higher temperatures.

In addition to the analysis of the solid product, we wanted to gain further understanding on the origin of the different chemical structures by complementary analysis of the liquid residuals after synthesis. As known from the literature the typically byproducts of the hydrothermal carbonization of glucose are hydroxymethyl furfural (HMF), levulinic acid and formic $\operatorname{acid}^{[3]}$. The acidic byproducts determine the final $\mathrm{pH}$ of the reaction mixtures, in particular for the experiments performed at higher starting $\mathrm{pH}$, as shown in Table 2. For experiments performed at starting $\mathrm{pH} 3$ or higher, the initial synthesis $\mathrm{pH}$ plays a minor role on the reaction which explains the similarities of the chemical structure of the final products. We determined the relative abundance of liquid products by HPLC for all experiments performed at different starting $\mathrm{pH}$. Interestingly, the concentration of levulinic acid, as well as the sum of acidic liquid byproducts, reaches a maximum for the initial synthesis $\mathrm{pH} 1.5$ which correlated to a minimum of total carbon yield (Figure 6). Since nitric acid is a strong oxidizing agent we expected the destructive oxidation of the liquid byproducts for the very high nitric acid concentrations at low $\mathrm{pH}$. The high mass balance deficit ${ }^{1}$ of about $40 \%$ for $\mathrm{pH} 0$ also points to the formation of gaseous byproducts (such as $\mathrm{CO}_{2}$ ), as does the slightly higher final $\mathrm{pH}$ for $\mathrm{pH}-0$-experiments (Table 2). The gradual decrease of the mass balance deficit was observed while increasing the $\mathrm{pH}$.

\begin{tabular}{|c|c|c|c|c|c|c|c|}
\hline Sample & $\mathrm{pH} 0$ & $\mathrm{pH} 1$ & $\mathrm{pH} 2$ & $\mathrm{pH} 3$ & $\mathrm{pH} 4$ & $\mathrm{pH} 5$ & $\mathrm{pH} 6$ \\
\hline $\mathrm{pH}_{0}$ & 0.1 & 1.1 & 2.0 & 3.0 & 4.0 & 5.0 & 6.0 \\
\hline $\mathrm{pH}_{\text {end }}$ & 2.8 & 2.3 & 2.0 & 2.1 & 2.2 & 2.2 & 2.2 \\
\hline
\end{tabular}

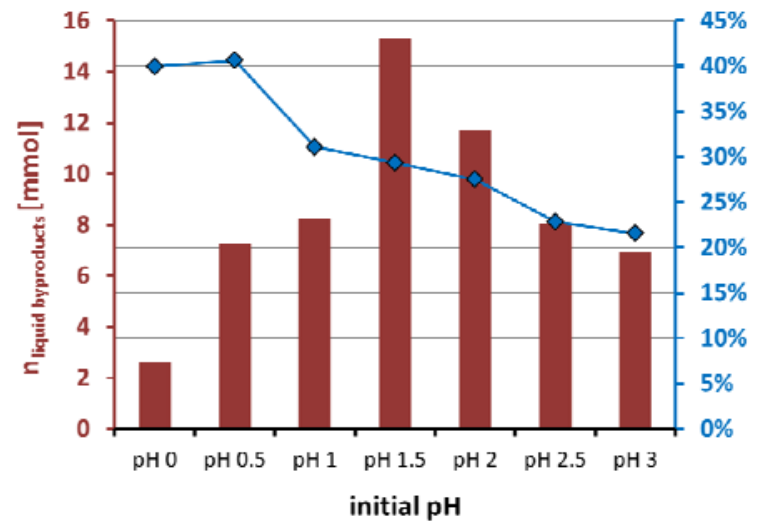

Figure 6. Amount of liquid byproducts and carbon balance deficit over $\mathrm{pH}$.

\footnotetext{
${ }^{1}$ The total mass balance was calculated based on the mass of the solid product and the sum of the liquid byproducts. Since the experimental set up does not allow quantification for gaseous byproducts, they are part of the carbon balance deficit.
}

To verify the process of destructive oxidation the stability of formic acid and levulinic acid was tested under reaction conditions in control experiments. $8 \mathrm{mmol}$ of each acid in $30 \mathrm{ml}$ aqueous nitric acid solution $(\mathrm{pH} 0-2)$ have been treated at $220^{\circ} \mathrm{C}$ for $6 \mathrm{~h}$. The decomposition was confirmed by HPLC analysis of the acid concentrations of the final solutions. The amount of remaining acids decreased with decreasing $\mathrm{pH}$ and hence followed the same trend as in the hydrothermal conversion of glucose.

\section{HTC synthesis at non-oxidative reference conditions}

The synthesis experiments were repeated with hydrochloric acid, yielding $\mathrm{HTC}_{\mathrm{HCl}}$ (Table 3) to study the combined effects of acidity and oxidizing potential exerted by the $\mathrm{HNO}_{3}$ reagent. The same morphological trends were found as for the

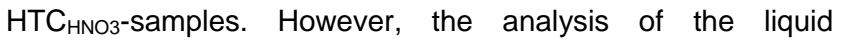
byproduct, as well as the total carbon yields showed significant differences in the lower $\mathrm{pH}$ regimes (Figure 7). For $\mathrm{HCl}$ catalyzed reactions the formation of liquid byproducts is promoted which leads to lower yields of solid product for lower starting $\mathrm{pH}$. Instead, high amounts of levulinic acid are obtained. Mechanistically, one mole of glucose can react into one mole of HMF and subsequently produce levulinic acid and formic acid in the ratio $1: 1$ by rehydration of the HMFintermediate ${ }^{[3]}$. In case of $\mathrm{pH} 0$, for the $\mathrm{HCl}$-catalyzed system, approximately $1 / 3$ of the initial glucose $(33 \mathrm{mmol})$ is converted into levulinic acid. However, the ratio between formic acid and levulinic acid is way below the expected ratio of $1: 1$. The reason lies in the acid catalyzed decomposition of formic acid. Only for $\mathrm{pH}>2$ the concentrations for formic acid and levulinic acid equalize.

The interpretation of the total carbon yields of $\mathrm{HTC}_{\mathrm{HNO}}$ and $\mathrm{HTC}_{\mathrm{HCl}}$ requires several control factors. The samples synthesized at $\mathrm{pH}$ 1.5-3 follow the same trend for both HTC materials. The increase in carbon yield with increasing $\mathrm{pH}$ can be correlated to the lower formation of liquid byproducts. Below pH 1.5 however, a positive effect of higher nitric acid concentrations on the final carbon yield can be observed for

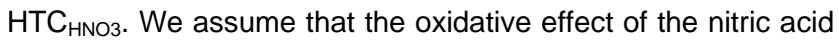
leads to reactive products, with a higher abundance of hydroxyl functional groups, which favor condensation reactions and polymerization. By further decrease in $\mathrm{pH}$, down to $\mathrm{pH} 0$, the decomposition prevails leading to lower yields in the carbon content.

\begin{tabular}{|cccccc|}
\hline \multicolumn{5}{|c|}{ Table 3. Elemental analysis of $\mathrm{HTC}_{\mathrm{HCl}}$ synthesized at different $\mathrm{pH}^{[\mathrm{a}]}$. } \\
$\mathrm{pH}^{[\mathrm{b}]}$ & $\mathrm{C}[\mathrm{wt} \%]$ & $\mathrm{H}[\mathrm{wt} \%]$ & $\mathrm{N}[\mathrm{wt} \%]$ & $\mathrm{O}[\mathrm{wt} \%]^{[\mathrm{b}]}$ & $\begin{array}{c}\text { Residual } \\
\text { mass after } \\
\mathrm{TG}[\mathrm{m} \%]\end{array}$ \\
\hline 0 & $70.8 \pm 0.2$ & $4.8 \pm 0.2$ & $0.53 \pm 0.04$ & $23.9 \pm 0.0$ & 54.5 \\
1 & $69.5 \pm 0.1$ & $4.7 \pm 0.0$ & $0.14 \pm 0.00$ & $25.7 \pm 0.1$ & 54.8 \\
2 & $68.7 \pm 0.2$ & $4.6 \pm 0.1$ & $0.08 \pm 0.01$ & $26.7 \pm 0.1$ & 55.1 \\
3 & $68.3 \pm 0.1$ & $4.5 \pm 0.0$ & $<0.1$ & $27.1 \pm 0.1$ & 54.0 \\
4 & $68.6 \pm 0.2$ & $4.5 \pm 0.0$ & $<0.1$ & $26.8 \pm 0.2$ & 53.7 \\
5 & $68.5 \pm 0.2$ & $4.5 \pm 0.0$ & $<0.1$ & $26.9 \pm 0.2$ & 53.4 \\
6 & $68.4 \pm 0.2$ & $4.5 \pm 0.0$ & $<0.1$ & $27.1 \pm 0.2$ & 53.8 \\
\hline
\end{tabular}

[a] Standard deviations were determined by minimum two separate experiments at the same initial synthesis $\mathrm{pH}$. [b] Initial synthesis $\mathrm{pH}$. [c] The oxygen is determined indirectly by subtraction of the $\mathrm{C}-, \mathrm{H}$ - and $\mathrm{N}$-content from $100 \%$, since other elements can be excluded. 

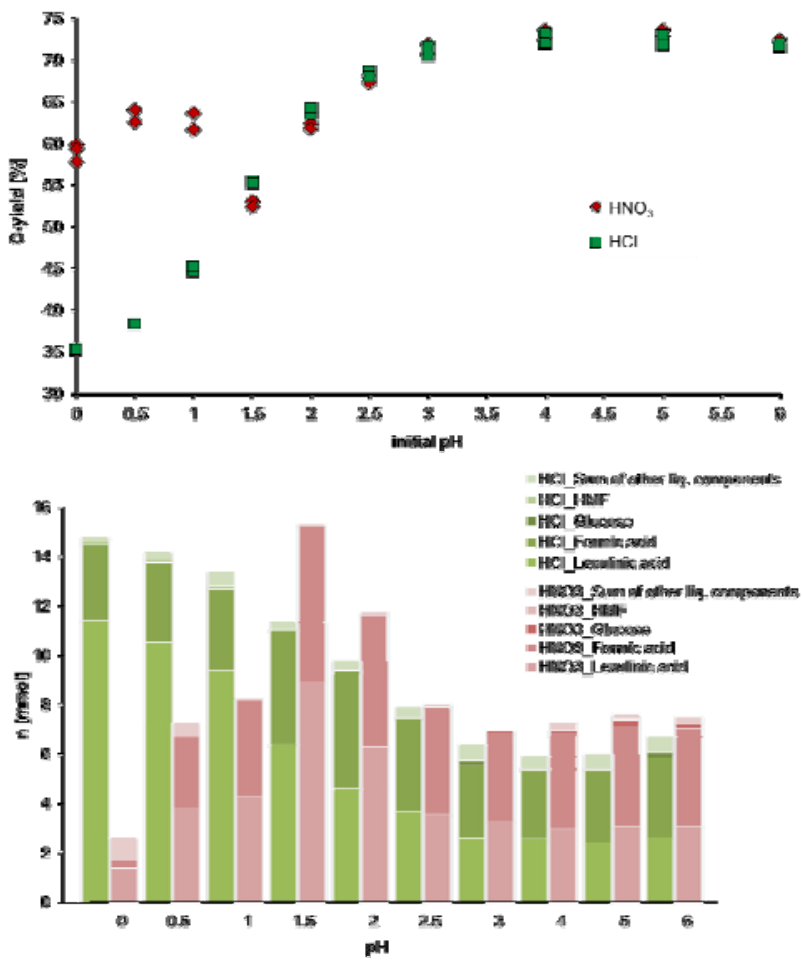

Figure 7. Upper graph: Comparison of the total carbon yield for $\mathrm{HTC}_{\mathrm{HCl}}$ and $\mathrm{HTC}_{\mathrm{HNO}}$. The total carbon yield is the product from the yield of the solid and its carbon content (from elemental analysis) divided by the theoretical carbon yield from the amount of glucose added. Lower graph: Amount of liquid byproducts as determined by HPLC analysis.

The chemical structure of the solid product was investigated by FT-IR (ATR) (Figure 8). Materials synthesized at $\mathrm{pH} 6$ show the same features, which is in line with the similar composition of liquid byproducts. Three characteristic bands can be identified at $1512 \mathrm{~cm}^{-1}, 1302 \mathrm{~cm}^{-1}$ and $1024 \mathrm{~cm}^{-1}$, as marked by asterix $\left({ }^{*}\right)$. All three bands disappear gradually when using higher acid concentrations. Since reference measurements of HMF exhibit features at $1522 \mathrm{~cm}^{-1}$ and 1020 $\mathrm{cm}^{-1}$, as well, the decrease of the characteristic bands can be interpreted as loss of the furanic structural motif in the polymer. The comparison of the materials synthesized at $\mathrm{pH} 0$ reveal several spectral differences. First, the broad band from 3005$3600 \mathrm{~cm}^{-1}$ points to a higher abundance of $\mathrm{OH}$-functional groups in the case of the $\mathrm{HNO}_{3}$-catalyzed HTC. Due to the oxidative strength of the nitric acid the higher abundance of $\mathrm{COOH}$-groups was expected and observed already by TG-MS measurements (Figure 5). Out of the three $\mathrm{CH}$-valence vibrations at $2952 \mathrm{~cm}^{-1}, 2927 \mathrm{~cm}^{-1}$ and $2873 \mathrm{~cm}^{-1}$, the outer ones are more pronounced in the case of the $\mathrm{HCl}$-catalyzed HTC. Their position indicates the abundance of aliphatic carbon for both $\mathrm{HCl}$ - and $\mathrm{HNO}_{3}$-catalyzed $\mathrm{HTC}$ materials. Only the type of aliphatic $\mathrm{CH}$-groups slightly differs with the acid used. Interestingly, distinct aromatic $\mathrm{CH}$-valence vibrations are not detected which points to highly cross-linked aromatic structures rather than linear chains of furanic or benzylic entities. The $\mathrm{C}=\mathrm{O}-$ to $\mathrm{C}=\mathrm{C}$-band ratio $\left(1700 \mathrm{~cm}^{-1}\right.$ and $1600 \mathrm{~cm}^{-1}$, respectively) are higher for $\mathrm{HCl}$-catalyzed $\mathrm{HTC}$, pointing to the lower abundance of $\mathrm{C}=\mathrm{O}$-functional groups in the case of $\mathrm{HNO}_{3}$-catalyzed $\mathrm{HTC}$. One reason for less carbonylic species may be a lower concentration of levulinic acid during $\mathrm{HNO}_{3}^{-}$ catalyzed HTC synthesis. Consequently, less levulinic acid can be incorporated into the carbonaceous structure during the polymerization process.
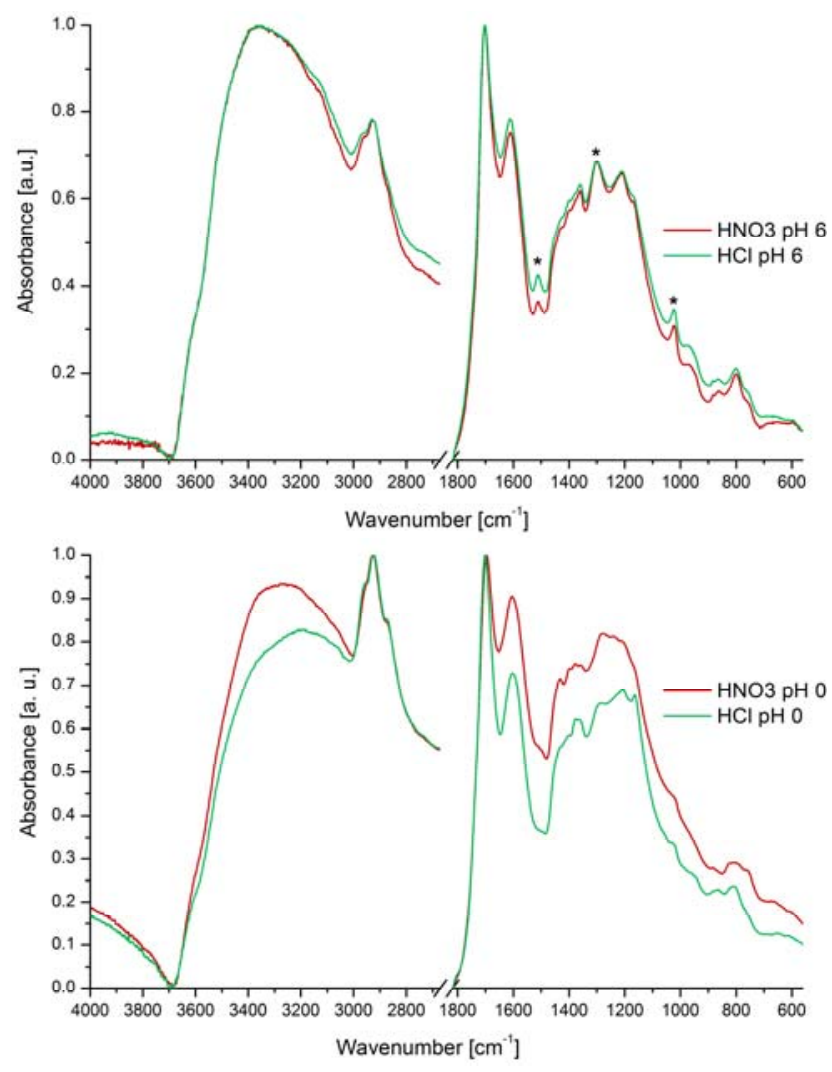

Figure 8. Comparison of FT-IR (ATR) spectra of $\mathrm{HTC}_{\mathrm{HCl}}$ and $\mathrm{HTC}_{\mathrm{HNO}}$, Upper graph: Comparison of materials synthesized at $\mathrm{pH}$ 6. Both spectra show the same features. The asterix $\left(^{*}\right)$ marks bands that are characteristic for the HTC synthesized at high pH (i.e. pH 6) with $1512 \mathrm{~cm}^{-1}, 1302 \mathrm{~cm}^{-1}$ and $1024 \mathrm{~cm}^{-1}$. All three bands disappear when using higher acid concentrations. Lower graph: Comparison of materials synthesized at $\mathrm{pH} 0$ showing several spectral differences.

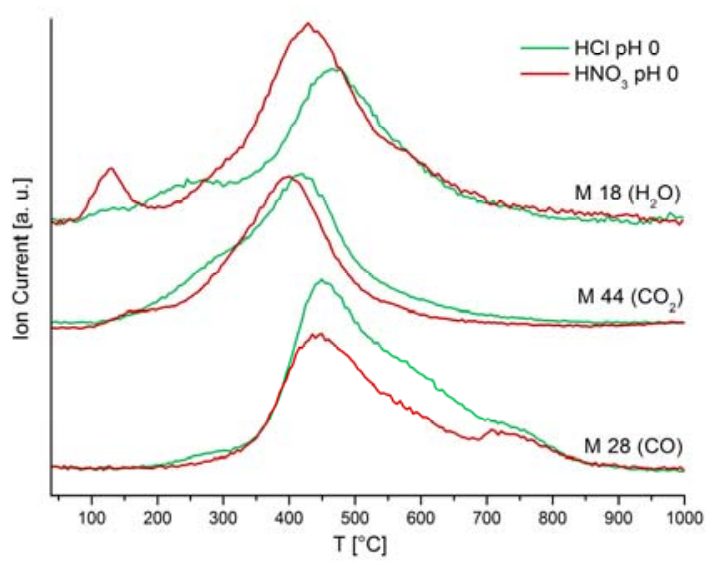

Figure 9. Comparison of MS signals from thermal decomposition of $\mathrm{HNO}_{3}$ $\mathrm{HTC}$ and $\mathrm{HCl}-\mathrm{HTC}$, both synthesized at the initial $\mathrm{pH}=0$. 


\section{ChemSusChem}

\section{Full Papers \\ www:chemsuschem.org}

Further evidence for structural differences of the carbonaceous products can be found in the TG-MS analysis (Figure 9). The more hydrophilic character of the carbon synthesized in $\mathrm{HNO}_{3}-$ acidified medium is expressed by the higher amount of water (mass 18) desorbed. Here, surface- adsorbed water molecules $\left(<200^{\circ} \mathrm{C}\right)$ can be distinguished from water derived from internal condensation reactions at higher temperatures $\left(\sim 400^{\circ} \mathrm{C}\right)$. Both features are more prominent for the $\mathrm{HNO}_{3}-$ catalyzed HTC. The higher abundance of carbonyl functional groups for $\mathrm{HCl}$-catalyzed $\mathrm{HTC}$, as already observed in the IR spectra, can be confirmed by the higher intensity of the CO signal (mass 28) in the evolved gas analysis

\section{Scale-up}

For the application of the HTC materials as catalyst or electrode supports, the reproducibility and scalability of the process is critical. Thus the influence of the initial synthesis $\mathrm{pH}$ on the final product properties was investigated exemplarily for the $\mathrm{pH}$ values of 0,3 and $6\left(\mathrm{HNO}_{3}\right)$ in twenty-five-fold scale-up synthesis runs. The transition from the $50 \mathrm{ml}$ unstirred autoclave into a stirred system of $2 \mathrm{I}$ did not result in identical products. The comparison of the elemental analysis of the materials is summarized in Table 4. The lower amounts of hydrogen detected for the materials from the scale-up points to a lower content of aliphatic hydrocarbon and a higher degree of condensation. The higher incorporation of nitrogen at $\mathrm{pH} 0$ reveals more functionalization by nitric acid. The abundance of oxygen increased accordingly.

\begin{tabular}{|cccccc|}
\hline \multicolumn{4}{|c|}{ Table 4. Elemental analysis of $\mathrm{HTC}_{\mathrm{HCl}}$ synthesized at different $\mathrm{pH}^{[\mathrm{a}]}$. } \\
$\mathrm{pH}^{[\mathrm{b}]}$ & $\begin{array}{c}\mathrm{C} \\
{[\mathrm{wt} \%]}\end{array}$ & $\begin{array}{c}\mathrm{H} \\
{[\mathrm{wt} \%]}\end{array}$ & $\begin{array}{c}\mathrm{N} \\
{[\mathrm{wt} \%]}\end{array}$ & $\begin{array}{c}\mathrm{O} \\
{[\mathrm{wt} \%]^{[\mathrm{b}]}}\end{array}$ & $\begin{array}{c}\text { Residual } \\
\text { mass after } \\
\mathrm{TG}[\mathrm{m} \%]\end{array}$ \\
\hline 0 (small) & 70 & 5.6 & 1.5 & 23 & 58.5 \\
3 (small) & 69 & 5.8 & $<0.1$ & 26 & 54.3 \\
0 (scale-up) & 66 & 4.0 & 2.0 & 28 & 57.4 \\
3 (scale-up) & 68 & 5.1 & $<0.1$ & 27 & 56.0 \\
6 (scale-up) & 67 & 4.5 & $<0.1$ & 29 & 54.8 \\
\hline
\end{tabular}

[a] Standard deviations were determined by minimum two separate experiments at the same initial synthesis $\mathrm{pH}$. [b] Initial synthesis $\mathrm{pH}$. [c] The oxygen is determined indirectly by subtraction of the $\mathrm{C}-\mathrm{H}, \mathrm{H}$ - and $\mathrm{N}$ content from $100 \%$, since other elements can be excluded.

Macroscopically the materials appeared more dense and darker than in the small scale experiments. The powder densities with $0.64 \mathrm{~g} / \mathrm{ml}$ for $\mathrm{pH} 0,0.62 \mathrm{~g} / \mathrm{ml}$ for $\mathrm{pH} 3$ and 0.39 $\mathrm{g} / \mathrm{ml}$ for $\mathrm{pH} 6$, are all above the values of the corresponding small scale experiments. The lower value for $\mathrm{pH} 6$ suggests also here a trend with $\mathrm{pH}$ variation.

A general tendency was found of HTC property parameters to shift towards those found for lower $\mathrm{pH}$ values as applied in the large-scale experiments. This underlines the notion made during the interpretation of the morphological parameters that two kinetically controlled reaction pathways compete during the process: the initial polymerization into a solid and the polycondensation of the initial product into a carbonaceous phase with six-membered rings by destruction of the initially present five-membered rings. We conclude that stirring and the removal of concentration gradients of the catalyzing acid in the large reactor is beneficial for the desired latter process of forming graphene-like structures with still appreciable functional group content. Care must thus be taken to observe the origin of HTC materials for further material synthesis. The relevant internal structure of HTC results from the details of their synthesis kinetics and not from the thermdynamics of a "fixed" pH value.
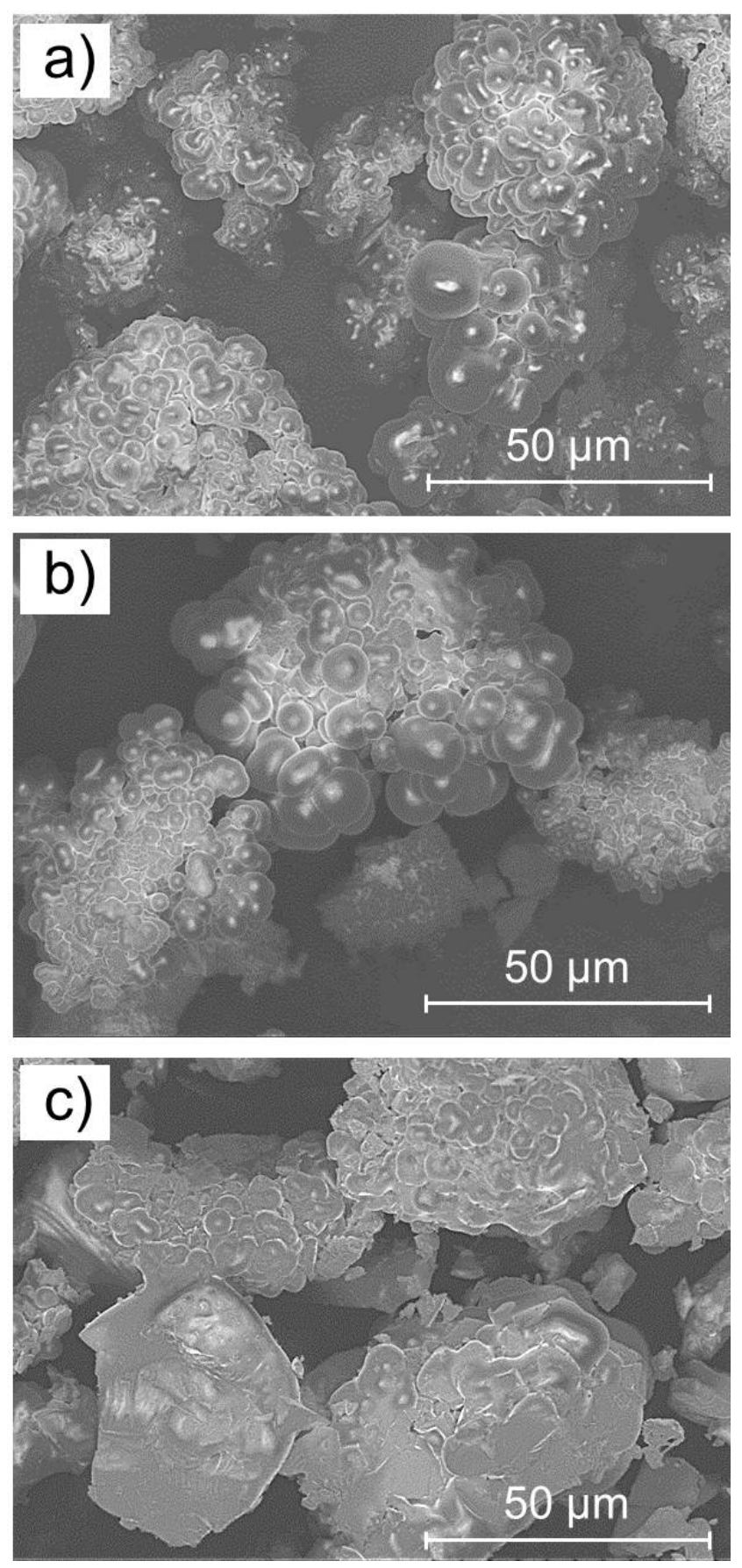

Figure 10. SEM micrographs of HTC materials from scale-up experiments with initial synthesis $\mathrm{pH} 6$ (a), $\mathrm{pH}^{3}$ (b), $\mathrm{pH} 0$ (c). 
The SEM micrographs show aggregates consisting of more or less spherical primary particles of different size (Figure 10). Whereas the spheres for the material prepared at $\mathrm{pH} 6$ are distinguishable and quite homogeneous in particle sizes and shape, the sample synthesized at $\mathrm{pH} 0$ exhibits rather random shaped aggregates with hardly observable primary particles of spherical shape. Hence, the aggregates can be seen as indication for higher material densities. The material prepared at $\mathrm{pH} 3$ reveals particles with characteristics of both samples mentioned before. By FT-IR spectroscopy (Figure 11), the ratio of the $(\mathrm{C}=\mathrm{O})$ - to $(\mathrm{C}=\mathrm{C})$-vibration signals for the large-scale $\mathrm{pH} 6$ synthesis is similar to the $\mathrm{pH} 0$ experiment in the small scale. In generally, both features are less prominent in the materials prepared in the scale-up experiments. This can be take as good indication for the higher degree of condensation towards a graphenic structure as expected from the increased presence of the catalyzing acid during condensation. Comparing scale-up experiments at different initial synthesis $\mathrm{pH}$, the carbonyl vibration is increasing with increasing $\mathrm{pH}$, whereas the $(\mathrm{OH})$-band increases with decreasing $\mathrm{pH}$.

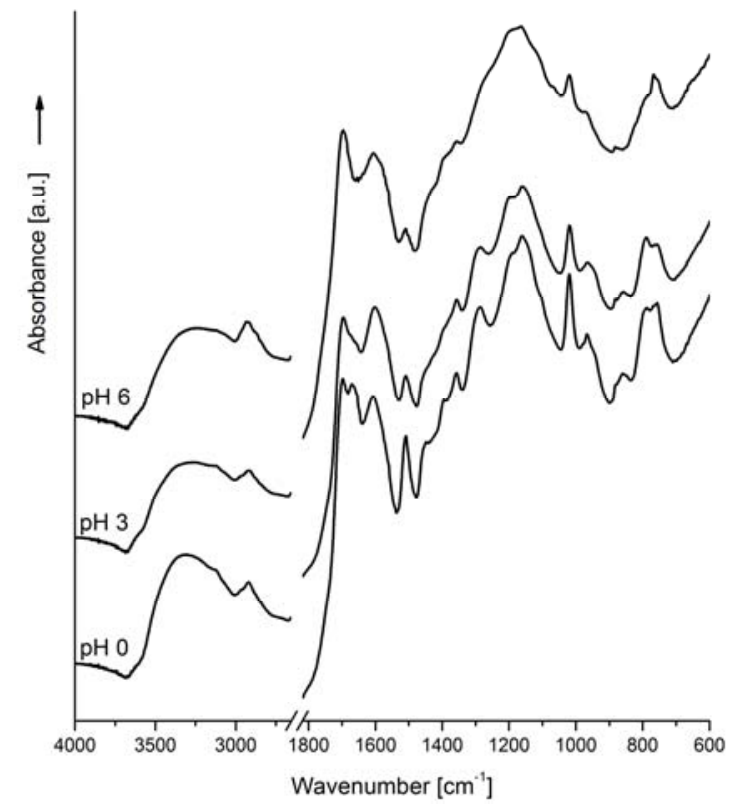

Figure 11. FT-IR spectra of scale-up experiments performed at the $\mathrm{pH}$ values indicated.

The Raman spectra (Figure 12) exhibit clearer signals and lower fluorescence levels for all three samples in comparison to the small-scale experiments. This is again the indication for higher extent of condensation in stirred experiments. The intensity ratios $\mathrm{I}_{\mathrm{D}} / \mathrm{I}_{\mathrm{G}}$ are with $0.80(\mathrm{pH} 0), 0.78(\mathrm{pH} 3)$ and 0.78 $(\mathrm{pH} 6)$ very similar. The $\mathrm{I}_{\mathrm{D}} / \mathrm{l}_{\mathrm{G}}$ ratio of the small scale experiment with the initial synthesis $\mathrm{pH}=0$ was determined to be 0.76 . For graphite related materials, such as soot or multi-walled carbon nanotubes (MWCNTs), the decrease of the $\mathrm{I}_{\mathrm{D}} / \mathrm{I}_{\mathrm{G}}$ ratio was used to describe the extent of graphitization and lower contribution of amorphous carbon residues ${ }^{[11]}$. In case of HTC, the materials are of amorphous nature consisting of a significant fraction of distinguishable molecular entities, as observed in the FT-IR spectra. As reported by Ferrari and Robertson ${ }^{[12]}$ the trend of the $I_{D} / I_{G}$ inverts for graphitic domains of less than $2 \mathrm{~nm}$ in size. Thus the observed trend is plausible for the growth of graphitic networks of from 1 to $1.5 \mathrm{~nm}$ in size (4-6 benzene rings edge length) and in line with the increase in thermal stability for the HTC prepared in the stirred reactor. As a caveat it is noted that this interpretation is based on the assumption of investigating oxygen free materials. A systematic study of the contribution of functionalization in nanocarbon to the trends of the Raman signals has not been reported so far.

Thermal analysis supports the insight into structural differences resulting from modified condensation kinetics. Figure 13 compares the relevant MS traces. The scale-up products are more hydrophobic and bind less structural water as can be seen from Figure 13 a. This indicates a higher extent of condensation. The mass fragment 28 (Figure $13 \mathbf{b}$ ) confirms a higher abundance of carbonyl species for materials synthesized under stirring at $\mathrm{pH}$ 6. The introduction of carboxylic acid functional group at high concentrations of nitric acid $(\mathrm{pH} 0)$ is evidenced by the $\mathrm{CO}_{2}$ evolution at approximately $250^{\circ} \mathrm{C}$ (Figure $13 \mathrm{c}$ ). The signal exceeds the $\mathrm{CO}_{2}$ evolution for the small scale experiment at $\mathrm{pH} 0$ significantly. For $\mathrm{pH} 3$ and $\mathrm{pH} 6$ the contribution of $\mathrm{CO}_{2}$-evolving functional groups is decreasing successively as found for the small-scale experiments.

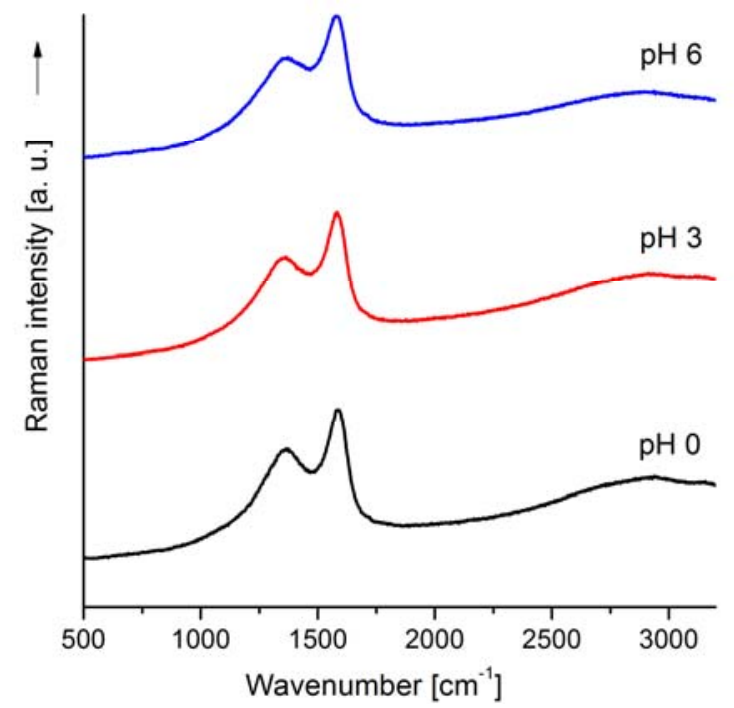

Figure 12. Comparison of Raman spectra for materials synthesized in the scale-up experiments.

In summary, the obtained results of the scale up experiments indicate that synthesis recipes cannot be directly transferred between the small-scale laboratory test autoclaves without stirring and a larger instrument with integrated stirring. This confirms the kinetic control of the structural features of HTC materials. Both dehydration and condensation were promoted during the scale up, which can be explained by the elimination of mass transport in the system during solidification (see SEM Figure 10) and later during condensation (Figures 11-13). However, the trends found for $\mathrm{pH}$ variation in terms of chemical functionalization, density and particle size are maintained while scaling up the process to approximately $100 \mathrm{~g}$ material yield. 


\section{ChemSusChem}

\section{Full Papers \\ www.chemsuschem.org}

a)

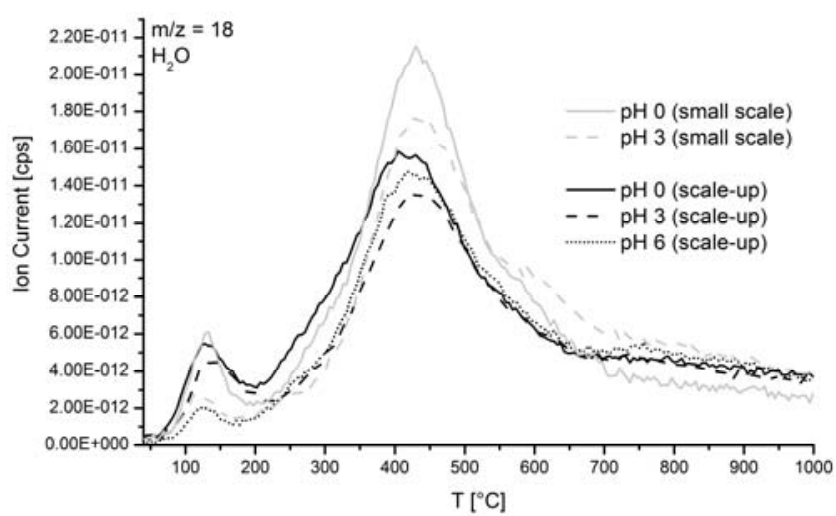

b)

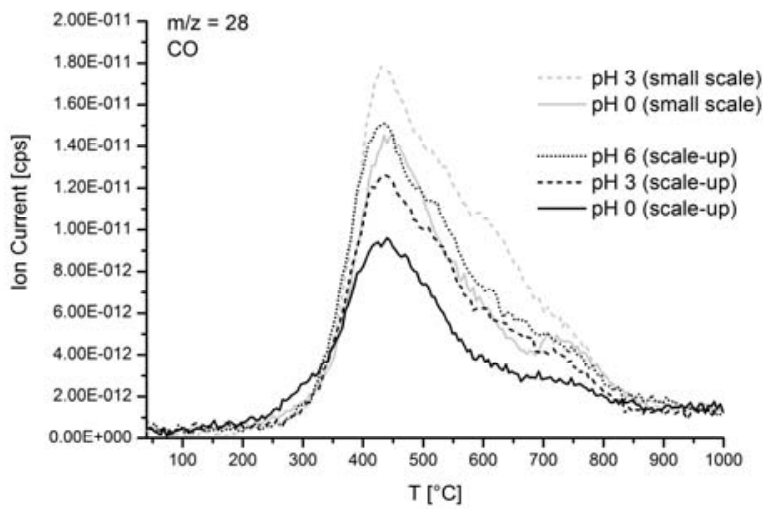

c)

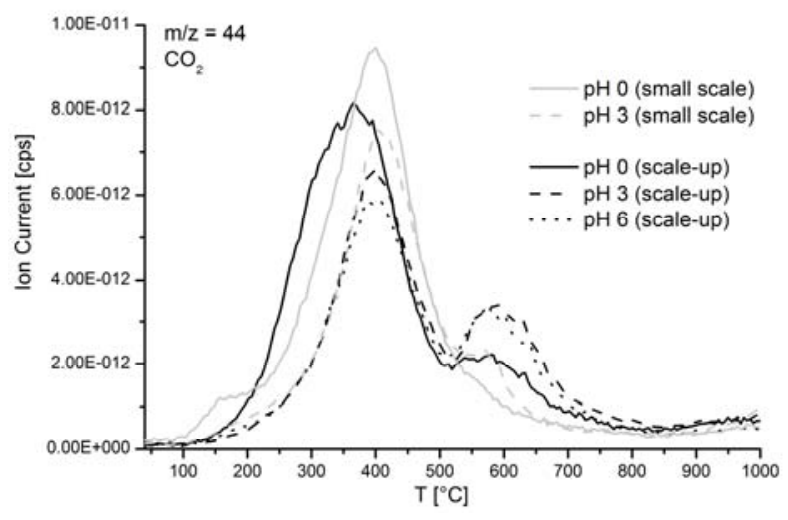

Figure 13. MS signals of a) $\mathrm{H}_{2} \mathrm{O}$, b) $\mathrm{CO}$ and c) $\mathrm{CO}_{2}$ fragments for $\mathrm{HTC}$ materials prepared in the scale-up experiments.

\section{Conclusions}

We demonstrated the influence of the synthesis $\mathrm{pH}$ as well as the oxidative strength of the catalyzing acid on physical and chemical properties of the resulting HTC. We show that with $\mathrm{pH}$ variation between $\mathrm{pH} 0$ to $\mathrm{pH} 6$ substantial changes in powder density and particle size can be achieved, in addition to the color change from black to brown with increasing $\mathrm{pH}$. The deepening color indicates the more extensive condensation of the carbonaceous network synthesized at $\mathrm{pH}<3$ as confirmed by Raman spectroscopy. Furthermore, a different abundance of oxygen functional groups with synthesis $\mathrm{pH}$ was detected by TG-MS and by IR-spectroscopy. The content of carbonyl functional groups was found increase with synthesis $\mathrm{pH}$.

For low synthesis $\mathrm{pH}$ the effect of the oxidizing acid $\mathrm{HNO}_{3}$ was manifested in the higher content of carboxylic acid functional groups, as well as in a higher yield of carbonaceous product. Finally, the complementary analysis of liquid products by HPLC provided insights on the effect of $\mathrm{pH}$ determining organic acids. These were incorporated into the highly condensed products as seen by the higher abundance of carbonyl functional groups with higher concentrations of levulinic acid.

The possibility of a transfer of $\mathrm{pH}$-dependent trends in structural properties into scale-up production was shown. We obtained homogeneous samples of HTC with controlled condensation properties on the $100 \mathrm{~g}$ scale sufficient to test them in various applications of chemo- and electro-catalysis. Care must be taken, however to develop synthesis protocols in small unstirred units and expect the results to be identical in lager units. This observation clearly indicates the origin of conflicting descriptions of HTC material properties obtained from nominally the same reaction mix under different kinetic conditions.

The structural insights into HTC synthesized under different $\mathrm{pH}$ can be used for the development of synthesis strategies for the introduction of specific functional groups including postsynthetic incorporation of nitrogen species. The higher abundance of functional groups at higher synthesis $\mathrm{pH}$ can be desired for further post-treatment / functionalization steps, for application as absorber materials or in catalysis. The higher condensed carbon scaffold with still significant amounts of functional groups obtained at low $\mathrm{pH}$ can be used for electrode materials requiring electrical conductivity and anchoring sites for electro-catalysts.

\section{Experimental Section}

The synthesis of the carbon materials was performed in teflon lined autoclaves heated in a heating block system to $220^{\circ} \mathrm{C}$ for $6 \mathrm{~h}$. For a typical experiment $30 \mathrm{ml}$ of a $20 \mathrm{wt} \%$ glucose solution were prepared in aqueous solution. The solution was acidified to the desired $\mathrm{pH}(0-6)$ by either nitric acid or hydrochloric acid prior glucose addition. The final product was named $\mathrm{HTC}_{\mathrm{HNO}}$ or $\mathrm{HTC}_{\mathrm{HCl}}$, respectively. After the hydrothermal treatment the autoclaves were taken out of the heating device and were allowed to cool down over night. The solid product was filtered and washed with water thoroughly. The supernatant was sampled and analyzed by HPLC (Agilent 1200 Series) for residual sugar and organic acid components over a ion exchange column based on sulfonated styrene divinyl benzene (REZEX ${ }^{\mathrm{TM}}$, RHM-Monosaccharide, $80^{\circ} \mathrm{C}, 0.6$ $\mathrm{ml} / \mathrm{min}$, eluent: $0.005 \mathrm{M} \mathrm{H}_{2} \mathrm{SO}_{4}$ ). The solid product was dried in vacuum at $60^{\circ} \mathrm{C}$ over night. The resulting hydrothermal carbon was analyzed by TG-MS (Netzsch ${ }^{\circledR}$ STA 449 F3 Jupiter ${ }^{\circledR}$ QMS4), FT-IR (ATR, Thermo Scientific ${ }^{\circ}$ Nicolet iS50), Raman (Thermo Scientific ${ }^{\circledR}$ DXR Raman Microscope, at $532 \mathrm{~nm}$ ) and SEM (Hitachi S-4800).

The scale-up experiments were performed in a stirred 2 Iautoclave made from Hastalloy $\mathrm{C} 21$, at a constant stirring rate of $400 \mathrm{rpm} .800 \mathrm{ml}$ of a $20 \mathrm{wt} \%$ glucose solution were used, acidified by $\mathrm{HNO}_{3}$ to $\mathrm{pH} 0, \mathrm{pH} 3$ and $\mathrm{pH} 6$, respectively. The temperature control was provided by an electric heat jacket and controlled by an internal thermocouple. The experiments 
were performed in controlled inert atmosphere $\left(\mathrm{N}_{2}\right)$ at a starting pressure of 8 bar. Before every experiment the system was purged by nitrogen ( 2 times at 30 bar). The complete temperature and pressure profile for the scale-up experiment can be found in the supplementary information.

\section{Acknowledgements ((optional))}

We would like to thank Wiebke Frandsen and Gisela Weinberg for SEM. Funding from the Max Buchner Foundation and the Max Planck Society is gratefully acknowledged.

Keywords: keyword 1 • keyword 2 • keyword 3 • keyword 4 • keyword 5

[1] M.-M. Titirici, M. Antonietti, Chemical Society Reviews 2010, 39, 103 116.

[2] R. J. van Putten, J. C. van der Waal, E. de Jong, C. B. Rasrendra, H. J. Heeres, J. G. de Vries, Chem. Rev. 2013, 113, 1499-1597.

[3] B. F. M. Kuster, Starch-Starke 1990, 42, 314-321.

[4] a) C. Falco, N. Baccile, M.-M. Titirici, Green Chemistry 2011, 13, 3273-3281; b) M.-M. Titirici, M. Antonietti, N. Baccile, Green Chemistry 2008, 10, 1204-1212

[5] a) N. Baccile, M. Antonietti, M.-M. Titirici, Chemsuschem 2010, 3 246-253; b) R. Demir-Cakan, P. Makowski, M. Antonietti, F. Goettmann, M.-M. Titirici, Catalysis Today 2010, 150, 115-118; c) Z. Li, N. Baccile, S. Gross, Z. Yuanjian, W. Wei, S. Yuhan, M. Antonietti,
M. M. Titirici, Carbon 2010, 48; d) R. Demir-Cakan, N. Baccile, M. Antonietti, M.-M. Titirici, Chemistry of Materials 2009, 21, 484-490.

[6] I. van Zandvoort, Y. H. Wang, C. B. Rasrendra, E. R. H. van Eck, P. C. A. Bruijnincx, H. J. Heeres, B. M. Weckhuysen, Chemsuschem 2013, 6, 1745-1758.

[7] A. Sadezky, H. Muckenhuber, H. Grothe, R. Niessner, U. Poschl, Carbon 2005, 43, 1731-1742.

[9] a) L. H. Yu, N. Brun, K. Sakaushi, J. Eckert, M. M. Titirici, Carbon 2013, 61, 245-253; b) B. Liu, Z. H. Zhang, K. C. Huang, Cellulose 2013, 20, 2081-2089; c) Z.-L. Xie, R. J. White, J. Weber, A. Taubert, M. M. Titirici, Journal of Materials Chemistry 2011, 21, 7434-7442; d) L. Xuezheng, X. Huiquan, S. Yongmiao, Q. Chenze, Materials Letters 2010, 64, 953-955955; e) H. Q. Xiao, Y. X. Guo, X. Z. Liang, C. Z. Qi, Mon. Chem. 2010, 141, 929-932; f) J. Ryu, Y. W. Suh, D. J. Suh, D. J. Ahn, Carbon 2010, 48, 1990-1998.

[10] a) J. L. Figueiredo, M. F. R. Pereira, Catalysis Today 2010, 150, 2-7; b) J. L. Figueiredo, M. F. R. Pereira, M. M. A. Freitas, J. J. M. Orfao, Ind. Eng. Chem. Res. 2007, 46, 4110-4115.

[11] a) C. Spudat, C. Meyer, C. M. Schneider, Phys. Status Solidi B-Basic Solid State Phys. 2008, 245, 2205-2208; b) B. Frank, A. Rinaldi, R. Blume, R. Schlogl, D. S. Su, Chemistry of Materials 2010, 22, 44624470.

[12] A. C. Ferrari, J. Robertson, Phys. Rev. B 2000, 61, 14095-14107

Received: ((will be filled in by the editorial staff))

Published online: ((will be filled in by the editorial staff)) 


\section{ChemSusChem}

Entry for the Table of Contents (Please choose one layout)

Layout 1:

\section{FULL PAPER}

Author(s), Corresponding Author(s)*

Page No. - Page No.

Title

Layout 2:

\section{FULL PAPER}

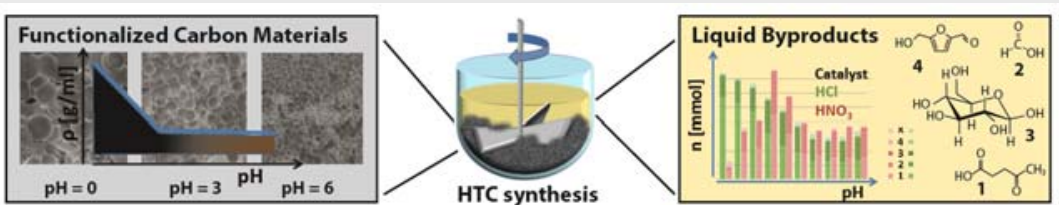

Specific control of morphology and chemical structure was studied by the control of the synthesis $\mathrm{pH}$ of the hydrothermal carbonization. The complementary analysis of liquid byproducts by HPLC reveals the potential implementation of the process into the biorefinery concept. Scale-up of the process in a stirred $2 \mathrm{I}$ batch reactor favours carbonization leading to higher condensed carbonaceous products. The relative trends of $\mathrm{pH}$ variation are maintained.
Sylvia Reiche*, Natalia Kowalew, Robert Schlögl

Page No. - Page No.

Influence of synthesis $\mathrm{pH}$ and oxidative strength of catalyzing acid on morphology and chemical structure of hydrothermal carbon 